\title{
Health and Safety Improvement Amongst Ghanaian Communities as A Corporate Social Responsibility of Construction Companies
}

\author{
Williams Justice*, Fugar Frank, Adinyira Emmanuel \\ Department of Construction Technology and Management, Kwame Nkrumah University of Science and Technology, Kumasi, Ghana \\ Email address: \\ Wjusticee30@yahoo.com (W. Justice), frankfugar@yahoo.com (F. Frank), rasadii@yahoo.com (A. Emmanuel) \\ ${ }^{*}$ Corresponding author \\ To cite this article: \\ Williams Justice, Fugar Frank, Adinyira Emmanuel. Health and Safety Improvement Amongst Ghanaian Communities as A Corporate Social \\ Responsibility of Construction Companies. American Journal of Construction and Building Materials. Vol. 3, No. 2, 2019, pp. $23-29$. \\ doi: 10.11648/j.ajcbm.20190302.11
}

Received: April 16, 2019; Accepted: May 21, 2019; Published: November 11, 2019

\begin{abstract}
Purpose-The purpose of this paper is to juxtapose construction site hazards with hazards present in typical Ghanaian communities to engender some safety knowledge transfer from construction companies to project host communities as a corporate social responsibility to the construction companies. Design/Methodology/Approach-Fifty-one volunteers who are health and safety professionals in Ghana part took in the survey to determine the common health and safety hazards present in most Ghanaian communities. The identified hazards were compared to typical construction site health and safety hazards identified from the literature. The survey also sought to establish the general health and safety awareness levels among Ghanaian communities. Findings - Findings of the study reveal that H\&S awareness in the Ghanaian community is poor, and therefore needs improvement. It also identified 26 construction hazards that are also common in the Ghanaian communities and established that H\&S knowledge in the Ghanaian construction industry is more advanced than that of the Ghanaian community. The findings further reveal that the respondent's perception of poor health and safety in the Ghanaian community was influence by their job positions in the communities. Originality/Value-The poor state of H\&S knowledge among Ghanaian communities has been recognized by various researchers, but this study is the first attempt to compare this state with the construction industry and to present a wide-ranging lesson to be learnt from health and safety improvement in the construction industry.
\end{abstract}

Keywords: Health and Safety, Hazards, Ghanaian Construction Industry, Safety Performance

\section{Introduction}

The poor state of health and safety culture among Ghanaian communities is well documented. This has generated a lot of debate among government, academia, religious bodies, opinion leaders and the media, all calling for an urgent action to improve upon the situation. National Statistical Service Report and the Ghana National Fire Service Incident Report have both called for an urgent need to improve the state of health and safety in the country $[12,13]$. Ignorance and negligence rank high as causes of most health and safety problems reported in the country. The responsibility of every nation is to provide a good and safe environment for its citizenry devoid of risks, hazards, and diseases [20].
Therefore, there is the need to put in place measures that protect the Ghanaian public against avoidable health and safety hazards.

\section{The Ghanaian Health and Safety Situation}

The need for health and safety improvement among Ghanaian communities has become paramount. This is because the Ghanaian society and its workforce is not exempted from daily exposure to hazards associated with the working environment such as; chemical hazards, physical hazards, biological hazards, psychological hazards 
and ergonomic hazards. According to Asumeng [7], Ghana is gradually becoming an industrialized nation and this change has exposed a large percentage of the workforce to various health and safety hazards. Annan et al., also opine that the increasing industrialization in Ghana is an indication of increasing number of the Ghanaian population being exposed to workplace physical, chemical, biological and psychological hazards [6]. As these authors have indicated, it is time for H\&S to be taken seriously in Ghana, because as the nation gradually moves towards industrialization, people are also moving away from traditional manual labour based work to service mechanization in most of their daily routines. Quartey and Puplampu [21], expressed the worrying nature of health and safety in the country, as employees complain about lack of effective policies, programs and practices that protect their well-being. With all these concerns Ghana as a nation does not have any comprehensive national OHS policy [6]. The few legal provisions in Ghana require huge modifications in order to meet international requirements and standards [11]. Recently there have been many avoidable domestic, industrial and institutional fire outbreaks coupled with vehicular collision which have been attributed to ignorance and negligence on the part of the citizenry $[6,9,12]$. Alkilani et al., [4], argues that health and safety awareness and performance in developing countries is low and therefore needs improvement.

Health and safety studies in Ghana have been in the ascendency in the country, although not as much as expected. Some authors such as Laryea, Kehni and AddoAbedi looked in the area of construction industry's health and safety improvement [19, 18, 2]. Quartey and Puplampu also looked at health and safety improvement among workers in the shipping and manufacturing industry [21]. Addai et al., Asumeng et al., as well as Annan et al., have all looked at general occupational health and safety improvement issues in the country $[9,7,6]$. However, none of these studies looked at similarities between H\&S hazards within the construction industry and typical Ghanaian communities and lessons that can be shared between the two. Therefore, this study, which is an ongoing research tries to fill in this gap of transferring improved H\&S knowledge of the construction industry to the Ghanaian community as a corporate social responsibility of the construction companies.

\subsection{Construction Health and Safety}

Occupational health and safety related issues at the work place, especially in the construction sector, continue to be of global concern [3]. According to these authors, the construction industry in America, for instance accounted for $16 \%$ of fatal occupational injuries while employing $4 \%$ of the total workforce in 2011. The U. K. construction sector also accounted for $22 \%$ of fatal injuries while employing $5 \%$ of the total workforce in that same year. This confirms the fact that, the construction industry is one of the most hazardous industries in the world.
Nonetheless, a number of studies have reported an improvement in the situation. According Jaselskis the improvements of construction H\&S is as a result of increased adaptation of highly effective injury prevention strategies [16]. Esmaeili et al., corroborated this statement after many years by arguing that, health and safety in the construction industry have improved significantly in recent years and these improvements are attributed to the increased implementation of good safety policies and strategies adopted by construction companies [10].

A large body of literature exists which reveals the key factors driving better health and safety in the construction industry. Some of these factors are: safety regulations [17], safety policies, safety training, incentives and worker attitude towards safety [15], increased formal safety meetings with supervisors, sub-contractors and suppliers [10], and safety equipment usage, education and training [1]. All these authors agree that the adaptation of these driving factors has helped in improving the state of $H \& S$ in the construction industry.

A hazard is any situation, substance, activity, event, or environment that could potentially cause injury or ill health. Some of the situations that can be hazardous in the construction industry includes: slippery or uneven walking surface, cramped working conditions, badly ventilated areas, fall from height, noisy locations, poorly lit areas, and confined space. Others are dangerous tasks, heavy lifting, repetitive work, interpersonal conflicts, bullying, intimidation, explosions, fires, collision, vibrations, leaks, falling objects, chemical reactions, toxic substances and excavation [14].

\subsection{Methodology}

A questionnaire survey is an effective method to gain data on attitudes towards issues and causal relationships. Also, it is a widely used method to describe general perceptions about health and safety practices [3]. For this particular study, a questionnaire survey was selected as the method of data collection. A survey of health and safety professionals in Ghana was carried out to determine the common health and safety hazards present in most Ghanaian communities. The identified hazards were compared to typical construction site health and safety hazards identified from the literature. The survey also sought to establish the general health and safety awareness levels among Ghanaian communities.

An invitation was sent to health and safety professionals in the country to indicate interest. Interested respondents 75 were given a questionnaire by email to fill. Out of this, fifty-one questionnaires were answered and returned. The respondents completed a structured demographics and perception questionnaire. Since none of the respondents had a missing value in their responses, there was no exclusion of respondents from the final analysis. The scoring of knowledge and practice questions run from non-hazardous (Strongly Disagree) through to hazardous (Strongly Agree) practices provided by each respondent. The demographic 
characteristics of the respondents captured in the study included gender, job position, years of experience in health and safety management and region of residence. The population consisted of health and safety officers with a post-graduate diploma in occupational health, safety and environmental management in different professions. They were chosen, due to their in-depth knowledge and expertise in the subject matter. Statistical analysis was conducted using the statistical package for social sciences (SPSS) software. Comparison of mean values of identified health and safety hazards of construction industry also found in the Ghanaian community was carried out in order to rank them.

\section{Findings, Analysis and Discussion}

Table 1 shows the frequency and percentage distribution of the characteristics of respondents pertaining to their gender, job position, years of experience in health and safety and region of residence. The dominant work experience of the respondents surveyed is less than six years. On the other hand, a significant number of respondents have worked between 6 and 15 years. This implies that all the respondents have significant experience in health and safety to ensure reliability and accuracy of data.
Table 1. Characteristics of the Study Sample (source author: 2019).

\begin{tabular}{lll}
\hline Respondents' Characteristics & Frequency & Percentage \\
\hline Gender & 39 & \\
Male & 12 & 76.5 \\
Female & 21 & 23.5 \\
Job Position & 4 & 41.2 \\
Safety Officers (Mining) & 9 & 7.8 \\
Safety Officers (Building) & 8 & 17.6 \\
Safety Officers (Health Service) & 0 & 15.8 \\
Safety Officers (Project Mgr.) & 9 & 0 \\
Safety Officers (Civil) & & 17.6 \\
Others & & \\
Experience in Health \& Safety & 25 & \\
Less than 6 years & 13 & 29.0 \\
6-10 years & 12 & 23.5 \\
11-15 years & 1 & 2.0 \\
16-20 years & & \\
\hline
\end{tabular}

The regions of residence of the respondents sampled for this study show that, a significant majority i.e. $70.6 \%$ of the respondents are residents of the Greater Accra region. This is expected since most institutional head offices in Ghana can be found in this highly populated region (Greater Accra). The remaining was distributed as follows: Volta $7.8 \%$, Western 5.9\%, Brong Ahafo 5.9\%, Central 3.9\%, Ashanti 2\%, Upper West 2\% and Upper East 2\%. It is noteworthy that none of the respondents reside in the Eastern and Northern Regions.

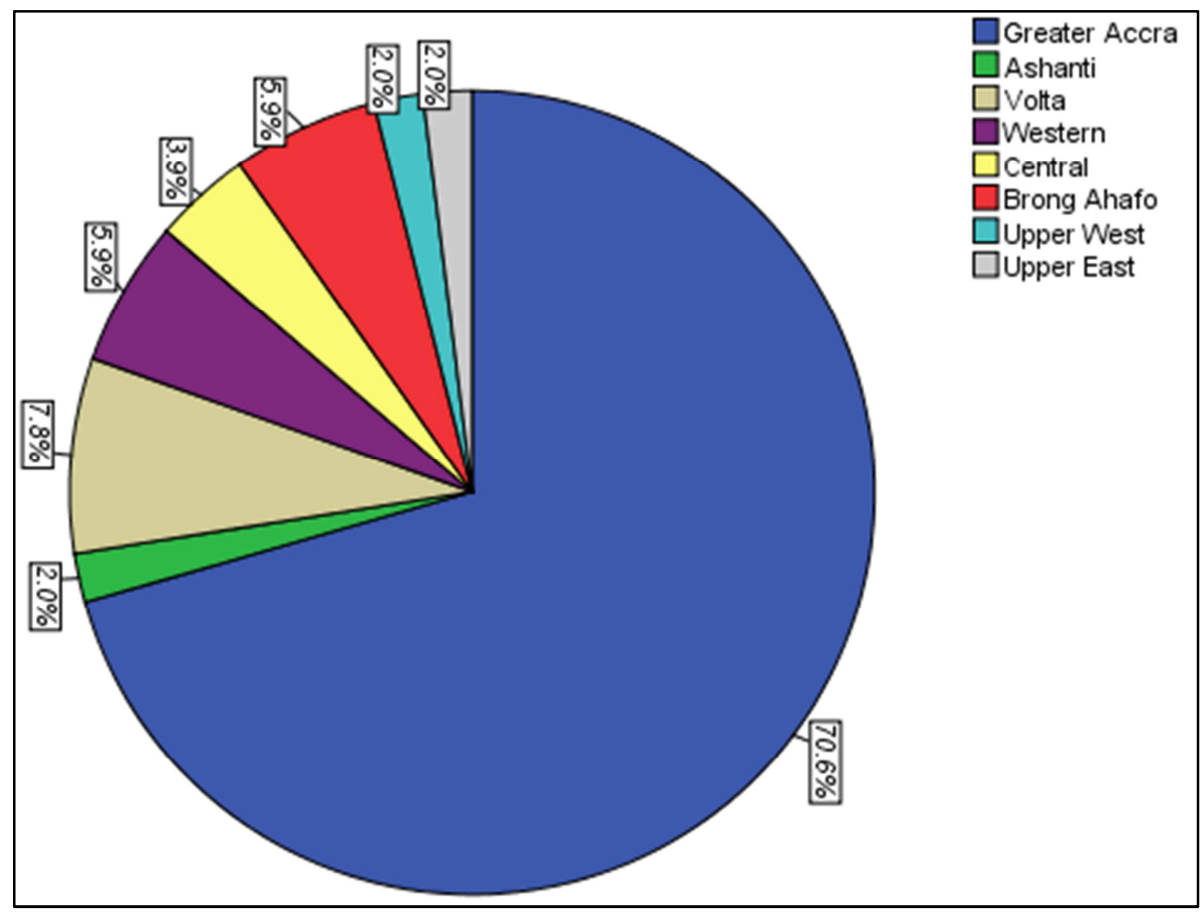

Figure 1. Regional residence of respondents (Source: 2019).

\subsection{Perception of Health and Safety Culture Within the Ghanaian Community}

This study describes frequencies of desirable answers (Agree and strongly agree) and undesirable answers (Strongly disagree, Disagree and Somehow Agree) provided for the perceptive questions (Figure 2). By and large, the bulk of the respondents (98.1\%) provided desirable answers (Agree and Strongly Agree) that health and safety knowledge of the Ghanaian communities is inadequate and needs enhancement. The finding is supported by Umeokafor who argued that, health and safety awareness and performance in developing countries are low [20]. Especially most of the respondents $(82.4 \%)$ strongly agree to the statement and 15 . 
$7 \%$ agree to that statement. However, $2.0 \%$, representing just one respondent have not agreed to the same statement. This could be due to weak health and safety legislation and lack of serious sanctions for health and safety accidents and violations in Ghana. Although the Ghanaian society fears the hazards, there is not much awareness creation on health and safety practices. Therefore, the findings are an indication that serious steps are required to address the problems of poor health and safety issues and practices in the country.

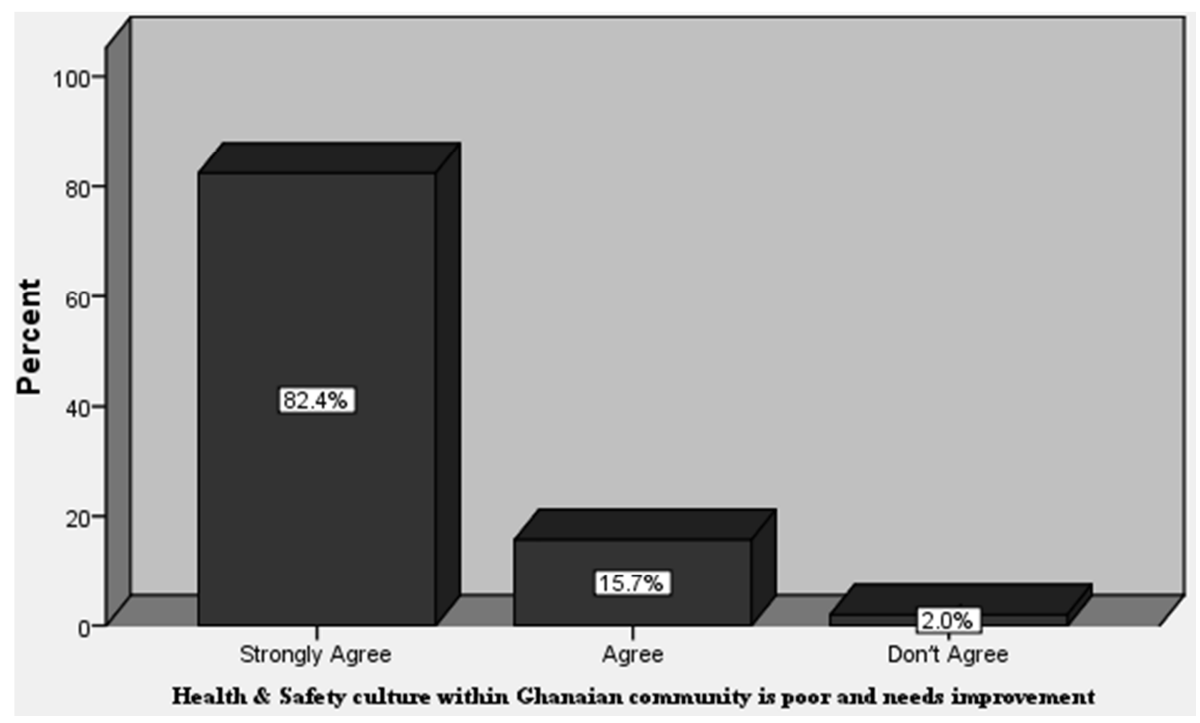

Figure 2. Health and Safety Culture within the Ghanaian Community (Source: Author 2019).

\subsection{Perception of Health and Safety Knowledge of the Ghanaian Construction Industry Compared with the Ghanaian Communities}

The perception of respondents of health and safety knowledge of the Ghanaian construction industry compared with that of Ghanaian communities is shown in Figure 3. Generally, the majority of the respondents $(84.3 \%)$ provided desirable answers (Agree and Strongly Agree) that health and safety knowledge of the Ghanaian construction industry is better compared with that of the Ghanaian community. This is matched against $(15.7 \%)$ who did not agree. Particularly most of the respondents (49.7\%) strongly agree with this position and $35.3 \%$ agree to same. However, $2.0 \%$, representing just one respondent strongly do not agree to same. This could be since health and safety management in the construction industry in Ghana is of major concern to stakeholders and government and also due to the risky nature of the industry and the proliferation of foreign contractors who have better knowledge in health and safety issues.

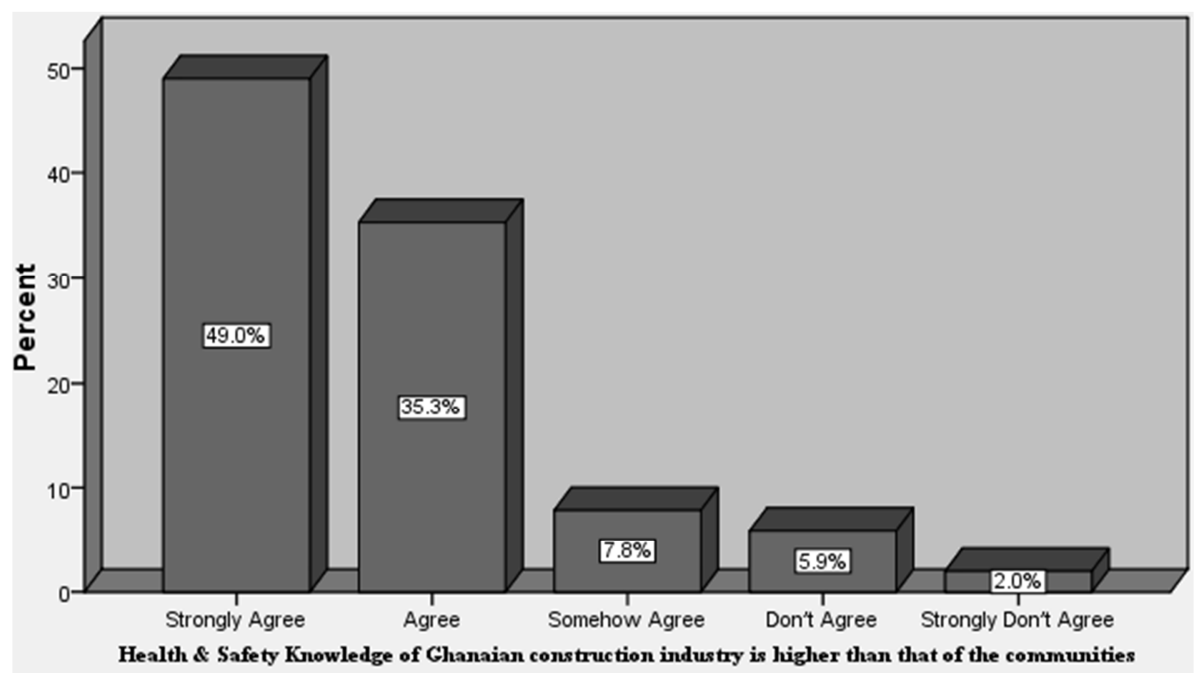

Figure 3. Health and safety knowledge of the Ghanaian construction industry compared with the Ghanaian communities (Source: Author 2019).

\subsection{Construction Hazards Commonly Found in Ghanaian Communities}

Respondents were required to show the hazards in the construction industry, which are usual in the Ghanaian community. The mean score ranking was used to analyse the responses. These hazards were ranked based on a Likert scale of 1 to 5 where " $1=$ strongly agree" and " $5=$ strongly 
disagree". A high mean relevance rating would mean that the construction hazard under consideration was not commonly found in the communities. From Table 2, it was observed that all the mean scores ( 26 out of 26 hazards) are less than 2.5 for all the respondents sampled in the study. The answers disclosed that "Dust" (mean = 1.31), "Equipment related injury" (mean = 1.59) "Manual handling" $($ mean = 1.59), and "Noise and vibration" (mean $=1.69$ ) are the first four major risks in the Ghanaian construction industry commonly encountered in the communities.

Table 2. Hazards of the Ghanaian Construction Industry (Source: Author 2019).

\begin{tabular}{|c|c|c|c|c|c|c|c|c|}
\hline \multirow{2}{*}{$\frac{\text { Hazards }}{\text { Dust }}$} & \multirow{2}{*}{$\begin{array}{l}\text { Mean } \\
1.31\end{array}$} & \multirow{2}{*}{$\begin{array}{l}\text { SD } \\
0.71\end{array}$} & \multirow{2}{*}{$\begin{array}{l}\text { t-value } \\
13.27\end{array}$} & \multirow{2}{*}{$\begin{array}{l}\text { p-value } \\
.000\end{array}$} & \multirow{2}{*}{$\begin{array}{l}\text { Mean Difference } \\
1.314\end{array}$} & \multicolumn{2}{|c|}{ 95\% CI of Difference } & \multirow{2}{*}{$\begin{array}{l}\text { Rank } \\
1\end{array}$} \\
\hline & & & & & & 1.11 & 1.51 & \\
\hline Equipment related injury & 1.59 & 0.85 & 13.30 & .000 & 1.588 & 1.35 & 1.83 & 2 \\
\hline Manual handling & 1.59 & 0.94 & 12.04 & .000 & 1.588 & 1.32 & 1.85 & 3 \\
\hline Noise and vibration & 1.69 & 0.79 & 15.30 & .000 & 1.686 & 1.46 & 1.91 & 4 \\
\hline Slips and trips & 1.80 & 0.87 & 14.77 & .000 & 1.804 & 1.56 & 2.05 & 5 \\
\hline Clearance and excavation & 1.88 & 1.01 & 13.27 & .000 & 1.882 & 1.60 & 2.17 & 6 \\
\hline Work place transport & 1.90 & 1.06 & 12.78 & .000 & 1.902 & 1.60 & 2.20 & 8 \\
\hline Falls from height & 1.92 & 1.15 & 11.97 & .000 & 1.922 & 1.60 & 2.24 & 9 \\
\hline Struck by objects & 1.98 & 0.95 & 14.91 & .000 & 1.980 & 1.71 & 2.25 & 10 \\
\hline Toxic substance in plant & 2.08 & 0.94 & 15.88 & .000 & 2.078 & 1.82 & 2.34 & 11 \\
\hline Vehicles collision & 2.08 & 1.02 & 14.60 & .000 & 2.078 & 1.79 & 2.36 & 12 \\
\hline Toxic substances (biological origin) & 2.10 & 0.86 & 17.53 & .000 & 2.098 & 1.86 & 2.34 & 13 \\
\hline Explosion & 2.12 & 0.97 & 15.55 & .000 & 2.118 & 1.84 & 2.39 & 14 \\
\hline Fumes & 2.12 & 1.03 & 14.65 & .000 & 2.118 & 1.83 & 2.41 & 15 \\
\hline Gases & 2.14 & 0.96 & 15.91 & .000 & 2.137 & 1.87 & 2.41 & 16 \\
\hline Exposure (contagious disease) & 2.16 & 1.14 & 13.54 & .000 & 2.157 & 1.84 & 2.48 & 17 \\
\hline Collision & 2.18 & 1.01 & 15.33 & .000 & 2.176 & 1.89 & 2.46 & 18 \\
\hline Mists & 2.20 & 1.06 & 14.81 & .000 & 2.196 & 1.90 & 2.49 & 19 \\
\hline Heat \& cold temperature & 2.20 & 1.15 & 13.65 & .000 & 2.196 & 1.87 & 2.52 & 20 \\
\hline Radiation (ionizing \& non-ionizing) & 2.25 & 0.89 & 18.08 & .000 & 2.255 & 2.00 & 2.51 & 21 \\
\hline Liquids & 2.25 & 0.91 & 17.64 & .000 & 2.255 & 2.00 & 2.51 & 22 \\
\hline Vapours & 2.25 & 1.07 & 14.99 & .000 & 2.255 & 1.95 & 2.56 & 23 \\
\hline Animal attacks (snake bites, etc.) & 2.29 & 0.97 & 16.97 & .000 & 2.294 & 2.02 & 2.57 & 24 \\
\hline Carcinogen (wood dust) & 2.47 & 1.03 & 17.19 & .000 & 2.471 & 2.18 & 2.76 & 25 \\
\hline Lung infection due to soil fungus & 2.47 & 1.17 & 15.05 & .000 & 2.471 & 2.14 & 2.80 & 26 \\
\hline
\end{tabular}

Other equally common hazards included "slips and trips" (mean =1.80); "clearance and excavation" (mean =1.88); "workplace transport" (mean =1.90); "fire" (mean =1.90); "falls from heights" (mean =1.92); "struck by objects" (mean $=1.98$ ). The construction hazards which were found to be less prevalent in the communities were; "carcinogen from wood dust" (mean $=2.47$ ), and "lung infection due to soil fungus" (mean $=2.47$ ).

Moreover, from table 2, mean scores of all the hazards evaluated were evidently much less than the neutral score of 3 (theoretical mean) at a 5\% significance level when the t-test was applied (all p-values $<0.05$ ). It is also clear that all the mean differences fell within the 95\% confidence interval constructed for each hazard item. Thus, all the hazards listed in Table 2 are potential hazards found in the communities. This finding is in agreement with Bhavana et al., [8] who posited that when safety hazards of a working environment are not identified, risky behaviour, and the likelihood of injuries can increase. Thus, the identification of potential risks present in the Ghanaian community marks the beginning of improving the safety situation amongst the people. Who would now be aware of the sort of hazards present in the communities and take precautions against such.

\subsection{Respondents' Characteristics and Their Perception of Health and Safety in the Ghanaian Construction Industry Compared to the Community}

Table 3 displays result of the chi-square test of association of the respondents' characteristics and their perception of the knowledge of health and safety in the Ghanaian construction industry. The items that were significant at $\mathrm{p} \leq 0.10$ are marked. It was observed that, respondents' gender ( $\mathrm{p}$-value $=$ $0.59)$, experience in health and safety $(\mathrm{p}$-value $=0.51)$ and region of residence $(p$-value $=0.64)$ were not statistically significantly related to their perception that health and safety knowledge in the construction industry is higher as compared to that within the Ghanaian community. This implies that, the respondents' perception that health and safety knowledge in the Ghanaian construction industry is higher compared to that of the community has got nothing to do with these characteristics.

Meanwhile, respondents' job position was found to be statistically significantly related to their perception that health and safety knowledge in the construction industry is higher compared to that within the Ghanaian community ( $\mathrm{p}$-value = $\left.0.09^{*}\right)$. This implies that there is enough statistical evidence to 
the fact that the occupational position of the respondents owns a substantial bearing on concluding that health and safety knowledge in the building industry is higher compared to that within the Ghanaian community. In other words, respondents perceived that health and safety knowledge in the Ghanaian construction industry is higher compared to that within the community based on their job position.

Table 3. Chi-Square Test p-values from the Cross Tabulation of the respondents' characteristics and the perception of Health and Safety Knowledge of the Ghanaian Construction Industry compared with the Communities (Source: Author 2019).

\begin{tabular}{ll}
\hline Respondents' Characteristics & Perception of Health \& Safety knowledge of the Ghanaian construction industry compared with the communities \\
\hline Gender & 0.59 \\
Job Position & $0.09 *$ \\
Experience in Health \& Safety & 0.51 \\
Region of Residence & 0.64 \\
\hline
\end{tabular}

* Significant at 0.10 .

\subsection{Respondents' Characteristics and Their Perception of Health and Safety Knowledge Within the Ghanaian Community}

Table 4 Displays a chi-square analysis applied to the relationship between respondents' characteristics and their perception of health and safety knowledge within the Ghanaian Community. The items that were significant at $\mathrm{p} \leq$ 0.10 are marked. It was observed that, the respondents' gender $(p$-value $=0.60)$, experience in health and safety $(p-$ value $=0.19)$ and region of residence $(p$-value $=0.84)$ were not statistically significantly related to their perception that health and safety knowledge within the Ghanaian community is poor and need enhancement This means that, the respondents' perception that health and safety knowledge within the Ghanaian community is poor and need enhancement has got nothing to do with these characteristics.

Meanwhile, respondents' job position was found to be statistically significantly related to their perception that health and safety knowledge within the Ghanaian community is poor and need an enhancement $\left(p\right.$-value $\left.=0.08^{*}\right)$. The job status of the respondents has a significant bearing to determine their judgement on whether the health and safety knowledge within the Ghanaian community is poor and need enhancement or not. In other words, respondents who perceive that health and safety knowledge in the Ghanaian community is poor and therefore needs enhancement are more likely to be influenced by their job position.

Table 4. Chi-Square Test p-values from the Cross Tabulation of the respondents' characteristics and the perception on Health and Safety knowledge within the Ghanaian Communities (Source: Author 2019).

\begin{tabular}{ll}
\hline Respondents Characteristics & Perception of Health \& Safety culture within the Ghanaian community \\
\hline Gender & 0.60 \\
Job Position & $0.08^{*}$ \\
Experience in Health \& Safety & 0.19 \\
Region of Residence & 0.84 \\
\hline
\end{tabular}

* Significant at 0.10 .

\section{Conclusions and Recommendation}

\subsection{Conclusion}

In conclusion, the current study sought to identify health and safety hazards presents in the Ghanaian community. The objectives of the study were met. There is a worrying state of health and safety within Ghanaian communities. From this study, several safety related hazards were found to be present in most Ghanaian communities, first among these being the presence of dust, equipment related injury, "manual handling and "noise and vibration. Hazards identified when compared to typical construction site safety hazards showed some similarities. There is therefore the need to pay attention to issues of health and safety in communities in order to improve the general welfare of the inhabitants.

Construction companies have a far better safety culture than exists in communities. The transfer of this improved safety culture from construction companies to communities has the potential to greatly improve the safety culture of communities.

Furthermore, when it comes to common H\&S hazards in the Ghanaian communities, 26 construction hazards were found to be common in the Ghanaian communities and consequently all the already existing knowledge in identification, mitigating and possible evacuation of such fortunes in the building industry can be transplanted to the Ghanaian communities to help improve their awareness level of these fortunes, keep them safe and to improve their welfare.

The study also found that the perceived level of health and safety awareness in the Ghanaian community was not influenced by the respondents Region of residence or their gender but based on their work experience. Additionally, the occupational positions of the respondents own a substantial bearing on their conclusion that health and safety knowledge in the construction industry is higher compared to that within the Ghanaian community. In other words, respondents perceived that health and safety knowledge in the Ghanaian construction industry is higher 
compared to that within the community based on their job position in the community.

\subsection{Recommendations}

It is therefore recommended that further studies should be carried out to find out ways in which H\&S knowledge of the construction industry can be transferred to the communities. Health and safety issues in the country should be a collaborative effort, involving government, academia, employers, as well as the entire citizenry. Construction activities cut across the whole country, whatever one does or wherever one goes in this country, there is construction, and the industry also employs both skilled and non-skilled labour wherever it happens. Construction should therefore be a secure channel or means of reaching out to the people when it does to creating awareness regarding H\&S. It's also recommended that the culture of safe living should be inculcated into the Ghanaian citizenry right from our communities so our environments shall also be saved as well as our workplaces. A national policy for direct handling of $\mathrm{H} \& \mathrm{~S}$ in the country, which provides strategies on how to identify, assess, manage or control hazards found to be present in the communities are recommended.

\section{References}

[1] Abdelhamid, T. S., \& Everett, J. G. (2000). Identifying root causes of Construction Accidents. Journal of Construction Engineering and Management, 52-60.

[2] Addo-Abedi, F. Y. (1999). Sustained development of the local contracting industry in a developing country. Proceedings of the Second International Conference on Construction Industry Development.

[3] Albert, A., Hallowell, M. R., Kleiner, B., Chen, A., \& Golparvar-Fard, M. (2014). Enhancing Construction Hazard Recognition with High-Fidelity Augmented Virtuality. Journal of Construction Engineering Management, 1943-7862.

[4] Alkilani, S. Z., Jupp, J., \& Sawhney, A. (2013). Issues of construction health and safety in developing countries: a case of Jordan. Construction Economics and Building, 141-156.

[5] Anaman, K. A., \& Osei-Amponsah, C. (2007). Analysis of Causality Links Between the Growth of the Construction Industry and Growth of the Macro-Economy in Ghana. Construction Management \& Economics, 951-961.

[6] Annan, J.-S., Addai, E. K., \& Tulashie, S. K. (2015). A Call for Action to Improve Occupational Health and Safety in Ghana and a Critical Look at the Existing Legal Requirement and Legislation. Safety and Health at Work, 146-150.

[7] Asumeng, M., Asamani, L., Afful, J., \& Agyemang, C. B.
(2015). Occupational Safety and Health Issues in Ghana: Strategies for improving employee safety and health at workplace. International Journal of Business and Management Review, 60-79.

[8] Bhavana Pandit, Alex Albert, Yashwardhan Patil and Ahmed Jalil Al-Bayati 2018. Fostering Safety Communication among Construction Workers: Role of Safety Climate and CrewLevel Cohesion. International journal of environmental research and public health.

[9] Emmanuel Addai, Samuel. K. Tulashie, Joe-steven Annan and Isaac Yeboah (2016). Trend of fire outbreaks in Ghana and ways to prevent these incidents. Journal of safety and health, http://dx.doi.org/10.1016/j.shaw.2016.02.004.

[10] Esmaeili, B. et al., 2012. Diffusion of Safety Innovations in the Construction Industry, (August), pp.955-963.

[11] Ghana Health Service Report. (2007). Accra.

[12] Ghana National Service Incident Report. (2016). Accra.

[13] Ghana National Statistical Service Report (2016). Accra.

[14] Health and safety executive (2011) U. K.

[15] Hinze, J., \& Wilson, G. (2000). Moving toward a zero injury objective." J. Constr. Eng. Manage.,. Journal of Construction Engineering and Management, 399-403.

[16] Jaselskis, E. J., Anderson, S. D., \& Russel, J. S. (1996). Strategies for Achieving excellence in Construction Health and safety Performance. Journal of Construction Engineering and Management, 61-70.

[17] Kartam, N. A., Flood, I., \& Koushki, P. (2000). Construction Safety in Kuwait: Issues, Procedures, Problems and Recommendations. Safety Science, 163-184.

[18] Kheni, N. A., Dainty, A. R., \& Gibb, A. G. (2008). Health and safety management in developing countries: a study of construction SMEs in Ghana. Construction Management and Economics.

[19] Laryea, S., \& Mensah, S. (2010). Health and safety on construction sites in Ghana, The Construction, Building and Real Estate Research Conference of the Royal Institution of Chartered Surveyors (pp. 2-3). Paris: Dauphine University.

[20] Nnedinma Umeokafor, (2018) "Community interventions in construction health and safety and the implications: Evidence from Nigeria", Journal of Financial Management of Property and Construction, Vol. 23 Issue: 3, pp.312-329, https://doi.org/10.1108/JFMPC-10-2017-0041 Permanent link to this document: https://doi.org/10.1108/JFMPC-10-20170041 .

[21] Samuel Howard Quartey \& Bill Buenar Puplampu, Employee Health and Safety Practices: An Exploratory and Comparative Study of the Shipping and Manufacturing Industries in. Ghana International Journal of Business and Management; Vol. 7, No. 23; 2012 ISSN 1833-3850 E-ISSN 1833-8119 Published by Canadian Centre of Science and Education. 